\title{
Verification the Numerical Simulation of the Strip Drawing Test by its Physical Model
}

\author{
Emil Evin ${ }^{1, *}$, Miroslav Tomáš ${ }^{2}$, Marek Výrostek ${ }^{3}$ \\ ${ }^{1 *}$ Department of Automotive Production, Technical University in Košice, Mäsiarska 74, 04001 Košice, Slovakia \\ 2 Department of Computer Support of Technology, Technical University in Košice, Mäsiarska 74, 04001 Košice, Slovakia \\ ${ }^{3}$ Production Director, Zastrova a.S., SNP 86, 06101 Spišská Stará Ves
}

\begin{abstract}
When numerically simulate the stamping processes, it is important to define the friction coefficients in different regions. These depend on the deformation processes due to various stress-strain states in each area. In the deep drawing process, the friction conditions in the blankholder-blank-die area and blank-die radius area differ. The analytical models for the friction coefficients determination by strip drawing test are presented in the paper. The equations have been used to calculate the friction coefficients based on a physical model of the strip drawing test and its numerical simulation. The physical and numerical experiments have been performed on Zn coated IF steel DX54D with thickness $0.78 \mathrm{~mm}$. Hill48 yield law and Hollomon's hardening curve have been used as material characteristics when numerically simulated. The blank-holding forces 4 and $9 \mathrm{kN}$ have been set during the experiment and numerical simulation. Good conformity of numerical simulation and the physical model have been found when friction coefficients were calculated from analytical models including the ratio of drawing forces measured with fixed and rotated cylinder. Additionally, the normal contact pressure under the blankholder and on the die radius was evaluated from the numerical simulations. The highest value has been found at the die radius start.
\end{abstract}

Keywords: deep drawing, numerical simulation, strip drawing test, friction coefficient, physical model.

\section{Introduction}

Many factors influence the material formability (Fig. 1) and some of these have been studied by various authors: material properties (mechanical properties, microgeometry of contact surfaces) [1,2], geometry and microgeometry of die contact surfaces [3], blankholder pressure [4], applied lubricant [3, 5], etc. The accurate determination of these parameters on technological characteristics is ambiguous, because each single parameter may vary from case to case. Thus, their impact on formability is changed as well.

Nowadays, the numerical simulation and analysis allows applying the computer aided engineering in stamping process and die design, due to its continuous development and verification $[6,7]$. It is also possible to predict the influence of material properties, die geometry and processing parameters on sheet formability using simulation methods. These enable to optimize the utilization of material properties under specific conditions [7,8]. Along with the increasing importance of the numerical simulations in pre-production, the need for exact values of input data for simulation software becomes more and more important. These are 
important for the accurate description of both, material behaviour and contact conditions when deep drawing process is numerically simulated [58].

The very important parameter influencing the sheet metal formability is the friction coefficient. Various tests, such as radial strip drawing friction test, cup test, etc. exist to measure the friction coefficient under the specific combination of blank, die surface, die coating and a lubricant [912]. The tests usually model the material stressing at stamping processes. In the paper, we have been focused to predict the friction coefficient by numerical simulation of the strip drawing test. Its physical model have been used to verify the numerical simulation results.

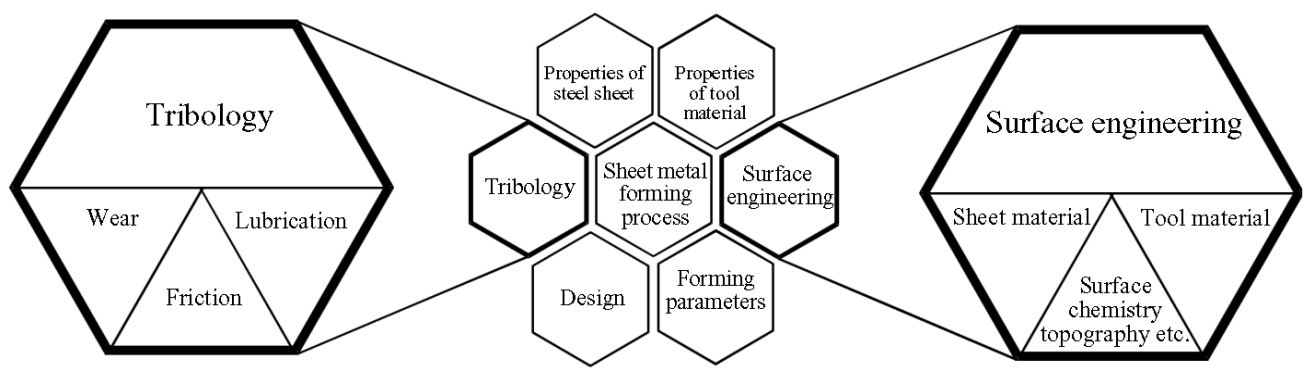

Fig. 1: Factors influencing the material formability of the sheet metal.

\section{Analysis of Forces on Contact Surfaces}

Various types of contacts between the steel sheet and the die occur in stamping process, such as deep drawing, stretching and bending - Fig. 2. The most frequent types of contacts occurred in stamping are shown in Fig. 2A, B: in Fig. 2A the strip slides between two flat die contact surfaces separated by lubricant; in Fig. 2B the strip is bent and slides on the drawing die radius.

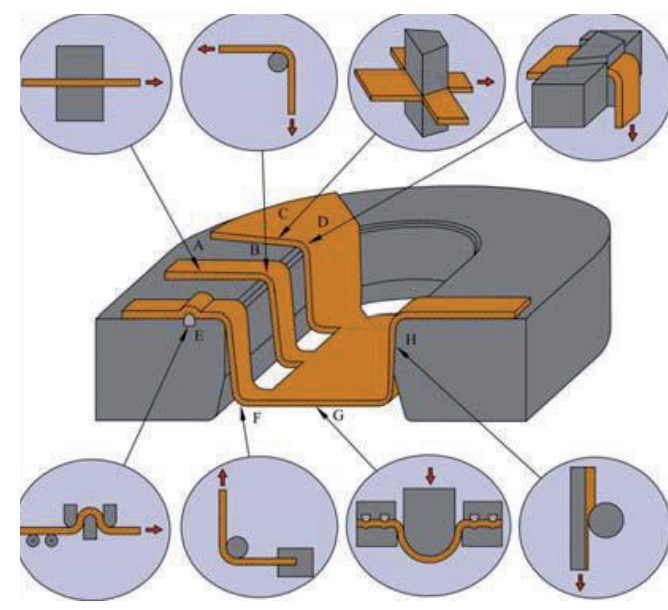

Fig. 2: Types of contacts at stamping processes.

Based on the models of contact types as presented, it is possible to analyze the majority of contacts for sheet metal stamping operations. To create the analytical model, following assumptions are considered:

- The contact pressure distribution on surfaces is non-homogeneous.

- The contact zone "blank and die" at the die radius - point A to point B (Fig. 3) - is expressed by bo.r. $r_{\text {d. }}$, where bo is initial blank width).

- Under the same conditions of stamping - material, lubricant, contact surfaces roughness, normal pressure - the friction coefficients on a flat and rounded surfaces are equal $[5,11,12]$.

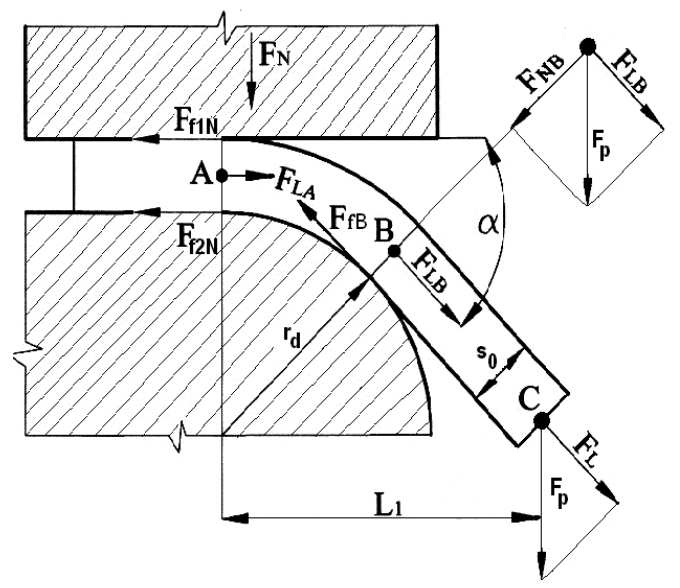

Fig. 3: Scheme of forces at strip drawing. a-wrapping angle of the die radius (the bending angle of the blank around the die radius).

The Coulomb's friction law is commonly used in simulation software. Based on modified Coulomb's 
law describing the blankholder-blank-die area, the friction force $F_{f 1 N}$ between the blank (or strip) and the blank-holder is determined as follows:

$$
F_{f 1 N}=2 \cdot f_{1} \cdot F_{N}
$$

where: $f_{1}$ is the coefficient of friction between the blank-holder and blank, $F_{N}$ is the blank-holding force.

During simultaneous strip drawing under the blank-holder and over the die radius, the strip in the point $A$ on the die radius is bent back - Fig. 3 . The backward bending force $F_{b A}$ in the point $\mathrm{A}$ is as follows:

$$
F_{b A}=\frac{M_{B}}{L_{1}}
$$

Thus, the bending moment $M_{B}$ of internal forces is calculated as follows $[8,9]$ :

$$
M_{B}=\frac{b_{0} \cdot k_{f} \cdot s_{0}^{2}}{4}
$$

where: $b_{0}$ - initial blank width, $s_{0}$ - initial blank thickness, $k_{f}$ - blank flow stress.

Since a reacting force at point $A$ is a result of both forces $F_{N}$ and $F_{b A}$ with the same value respectively, the friction force $F_{f 2 N}$ between the blank and the die is calculated as follows $[5,12]$ :

$$
F_{f 2 N}=\left(F_{N}+F_{b A}\right) \cdot f_{2}
$$

Thus, the total friction force $F_{f A}$ at point A is calculated as follows:

$$
F_{f A}=F_{N} \cdot f_{1}+\left(F_{N}+F_{b A}\right) \cdot f_{2}
$$

where: $F_{f 1 N}, F_{f 2 N}$ are friction forces and $f_{1}, f_{2}$ are friction coefficients between flat dies.

When the friction coefficients $f_{1}$ (blank-holder to blank) and $f_{2}$ (blank to die) are assumed equal, then the friction coefficient is calculated as follows [5, 12]:

$$
f_{1,2}=\frac{f_{1}+f_{2}}{2}
$$

Thus, the total friction force $F_{f A}$ in the point $\mathrm{A}$ is as follows:

$$
F_{f A}=2 \cdot f_{1,2} \cdot F_{N}+F_{b A} \cdot f_{1,2}
$$

Including the belt friction equation into the calculations, the longitudinal drawing force $F_{L}$ at point $A$ is as follows $[11,12]$ :

$F_{L A}=F_{f A} \cdot \exp \left(\alpha \cdot f_{3}\right)$

and $f_{3}$ is the friction coefficient on the die radius.

Contact length $L_{c r}$ between the blank and the die radius $r$ is expressed as follows:

$L_{c r}=r_{d} \cdot \alpha$

where: $\alpha$ is wrapping angle of the die radius, $r_{d}$ is the die radius.

When assume the wrapping angle $\alpha=\pi / 2$, then longitudinal drawing force $F_{L}$ is as follows:

$F_{L}=\left[\left(2 \cdot F_{N}+F_{b A}\right) \cdot f_{1,2}\right] \cdot e^{\frac{\pi \cdot f_{3}}{2}}$

and then

$F_{P}=F_{L}$

If the simulator with the rotate cylinder is supposed, the friction coefficient on the die radius $f_{3}=0$ and then the drawing (pulling) force $F_{p}$, when added into Eq. (11) and modified is calculated as follows:

$F_{p\left(f_{3}=0\right)}=\left(2 f_{1,2} \cdot F_{N}+F_{b A} \cdot f_{1,2}\right)$

If the friction coefficient is expressed from Eq. (12) in accordance with the Coulomb's law as a ratio of the drawing forces $\Delta F_{p_{1,2}}\left(f_{3}=0\right)$ difference to the blank-holding forces $\Delta F_{N_{1,2}}$ difference, due to the reference blank-holding force $F_{N_{l}}$, ref $=2 \mathrm{kN}$, the following equation is obtained:

$f_{1,2}=\frac{F_{p_{2}\left(f_{3}=0\right)}-F_{p_{1}, r e f\left(f_{3}=0\right)}}{2\left(F_{N_{2}}-F_{N_{1}, r e f}\right)}=\frac{\Delta F_{p_{1,2}\left(f_{3}=0\right)}}{2 . \Delta F_{N_{1,2}}}$

where: $F_{b A}$ is the bending force, $F_{N_{1}, r e f}=2 k N, F_{N_{2}}$ is the blank-holding force when $F_{N_{1}}$, ref $<F_{N_{2}}, F_{p_{2}}\left(f_{3}=0\right)$ is the drawing force measured at blank-holding force $F_{N_{2}}, F_{p_{1}, r e f\left(f_{3}=0\right)}$ is the drawing force measured at blank-holding force $F_{N_{l}}$,ref.

The stress on the contact areas the blankholderblank-die and the blank-die radius (see Fig. 2B) has been modelled by the simulator in the horizontal position with fixed cylinder - Fig. 6 . When assume the fixed cylinder, the friction coefficient on the die radius $f_{3}>0$ and then the strip drawing (pulling) 
force is calculated by the Oehler's formula as follows:

$$
\begin{gathered}
F_{p\left(f_{3}>0\right)}=F_{b A}+\left(2 f_{1,2} \cdot F_{N}+F_{b A} \cdot f_{1,2}\right) . \\
. \exp (\alpha \cdot \pi / 2)
\end{gathered}
$$

and:

$$
F_{p\left(f_{3}=0\right)}=F_{b A}+\left(2 f_{1,2} \cdot F_{N}+F_{b A} \cdot f_{1,2}\right)
$$

When Eq. (15) is added to Eq. (14) and then modified, following formula is obtained:

$$
F_{p\left(f_{3}>0\right)}=F_{p\left(f_{3}=0\right)} \cdot\left[\exp \left(\pi \cdot f_{3} / 2\right)\right]
$$

For the wrapping angle $\alpha=90^{\circ}$ or $\pi / 2$ (in radian), the friction coefficient $f_{3}$ on the die radius is calculated as follows:

$$
f_{3}=\ln \left(\frac{F_{p\left(f_{3}>0\right)}}{F_{p\left(f_{3}=0\right)}}\right) \frac{2}{\pi}
$$

where: $F_{p}\left(f_{3}=0\right)$ is drawing (pulling) force measured when the cylinder rotates, $F_{p}\left(f_{3}>0\right)$ is drawing (pulling) force measured when the cylinder is fixed, $f_{3}$ is friction coefficient on the die radius.

\section{Numerical simulation of the strip drawing test}

The strip drawing test numerical simulation has been realised using software Pam-Stamp2G. The experimental device was modelled in 3D CAD/ CAM software Pro/Engineer, and the components have been exported in a neutral format "igs". The die geometry has been the same as the geometry of the experimental testing device: the die radius $10 \mathrm{~mm}$, dimensions of flat die parts 30 in length and $50 \mathrm{~mm}$ in width (area of blank-holder). The die components and strip meshing have been done when imported into the Pam-Stamp 2G simulation software. The die components after meshing are shown in Fig. 4 and Fig. 5. To simulate various friction conditions under the blankholder and the die radius, the die was split into two parts, as it is shown in Fig. 5. Thus, the normal contact pressure has been calculated for each part separately.

Two types of contacts, shown in Fig. 2A, B, have been researched when numerically simulate the strip drawing test: the strip drawing with blank-

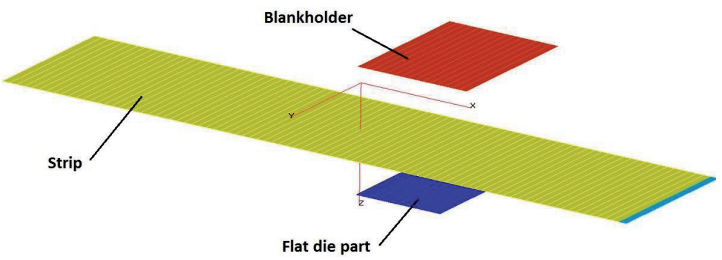

Fig. 4: The simulation model of the strip drawing test - strip drawing.

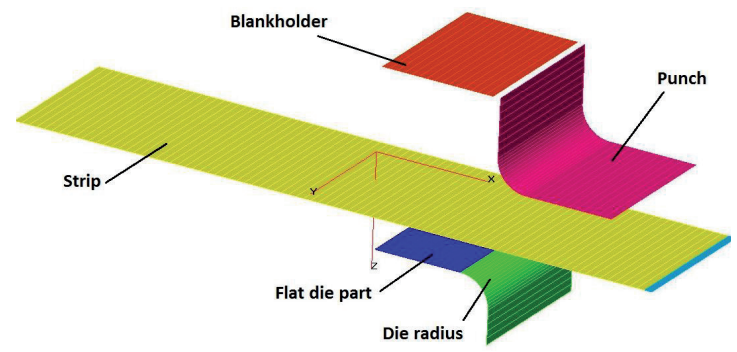

Fig. 5: The simulation model of the strip drawing test - strip bending and pulling.

holding (the strip was moved in the $x$-axis direction - Fig. ) at first, and the strip drawing with bending and pulling (the strip is bent and pulled in the z-axis direction - Fig. 5) at second.

The strip velocity $1 \mathrm{~m} / \mathrm{s}$ has been set in the corresponding axis during simulations. To measure the strip drawing (pulling) force, the section force attribute at the strip end nodes and elements was set. The blank-hoding force in the z-axis direction and "Accurate" contact type was applied during both simulation stages.

Experimental material DX54D has been used in simulation and Hollomon's hardening curve was defined according to measured data shown in Tab. 1. The orthotropic Hill48 material law was used as a yield law with Isotropic hardening definition. Orthotropic type of material anisotropy was defined by Lankford's coefficients according to measured data shown in Tab. 1. The material thickness was $0.78 \mathrm{~mm}$.

The numerical simulations have been performed for two various data sets shown in Tab. 2. The values have been chosen based on the experimental results of the strip drawing test using the experimental device in Fig. 6.

\section{Experiment of the strip drawing test}

The friction simulator (Fig. 6) has been used as a physical model of contact conditions on flat and 
Table 1: Material properties of DX54D - zinc coated IF steel sheet.

\begin{tabular}{|c|c|c|c|c|c|}
\hline Rolling direction & $\begin{array}{c}\text { Yield strength } \\
\mathbf{0 , 2 \%} \text { YS } \\
\text { [MPa] }\end{array}$ & $\begin{array}{c}\text { Ultimate tensile } \\
\text { strength UTS } \\
\text { [MPa] }\end{array}$ & $\begin{array}{c}\text { Material constant K } \\
\text { [MPa] }\end{array}$ & $\begin{array}{c}\text { Strain hardening } \\
\text { exponent } \mathbf{~ n} \\
{[-]}\end{array}$ & $\begin{array}{c}\text { Lankford's } \\
\text { coefficient r r } \\
{[-]}\end{array}$ \\
\hline $0^{\circ}$ & 170 & 292 & 492 & 0.208 & 1.98 \\
\hline $45^{\circ}$ & 180 & 304 & 503 & 0.203 & 1.04 \\
\hline $90^{\circ}$ & 184 & 297 & 487 & 0.215 & 1.59 \\
\hline average & 182 & 300 & 497 & 0.207 & 1.59 \\
\hline
\end{tabular}

Table 2: Data sets for numerical simulations.

\begin{tabular}{|c|c|c|c|}
\hline \multicolumn{1}{c|}{} & $\begin{array}{c}\text { Blank-holder force } \mathrm{F}_{\mathrm{N}} \\
{[\mathrm{kN}]}\end{array}$ & $\begin{array}{c}\text { Friction coefficient } \mathrm{f}_{\mathrm{1}, 2} \\
\text { (under blank-holder) } \\
{[-]}\end{array}$ & $\begin{array}{c}\text { Friction coefficient } \mathrm{f}_{3} \\
\text { (die radius) } \\
{[-]}\end{array}$ \\
\hline Set 1 & 4 & 0.125 & 0.08 \\
\hline Set 2 & 9 & 0.110 & 0.07 \\
\hline
\end{tabular}

curved regions of the die. The simulator enables physical modelling a load of contact surfaces both: under the blank-holder (Fig. 2a), when it is used with a rotating cylinder - the brake (pos.10 on Fig. 6) is off; and on the die radius (Fig. 2b), when it is used with a fixed cylinder - the brake (pos.10 on Fig. 6) is on.

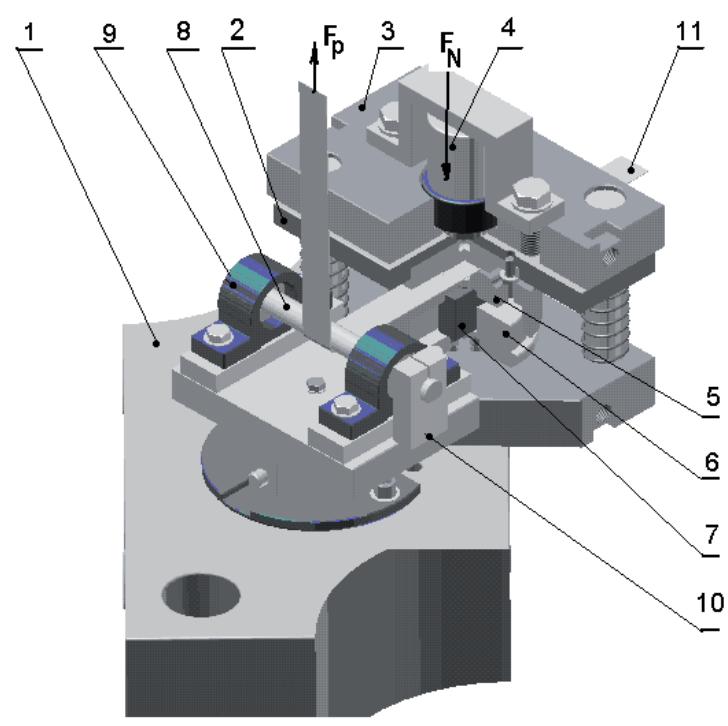

Fig. 6: The strip drawing test friction simulator.

1,2,3 - base, middle and upper plates, 4 - hydraulic clamping cylinder, 5,6upper and lower grips, 7 - blank-holding force load cell, 8 - cylinder, 9 - ball bearings, 10 - brake mechanism of the cylinder, 11 - strip.

The friction simulator has been fixed on testing machine Tiratest 2300 and the strip drawing (pulling) force was measured by the load cell. The strip drawing speed was $v=10 \mathrm{~mm} / \mathrm{s}$, the roughness of grips $R a=0.4 \mu \mathrm{m}$, the roughness of the cylinder $\mathrm{Ra}=0.4 \mu \mathrm{m}$. The strip has been lubricated with Anticorit Prelube 3802-39 S (kinematic viscosity $60 \mathrm{~mm}^{2} / \mathrm{s}$ at $40^{\circ} \mathrm{C}$ ) in the amount of $2 \mathrm{~g} / \mathrm{m}^{2}$. The experiments have been done for the blank-holder forces $\mathrm{FN}=4.0$ and $9.0 \mathrm{kN}$. The data has been recorded and processed by $P C$.

\section{Results and discussion}

The values of the strip drawing (pulling) force $F_{f 1 N}$ when experimentally measured and numerically simulated for the type of contact under the blankholder are shown in the Tab. 2. The values of friction coefficients $f_{1,2}$ calculated from the analytical equations (1) and (13) are also presented. Simulation and experiment conformity of the strip drawing force was $100.1 \%$ for the blank-holder force $4 \mathrm{kN}$ and $f_{\text {init }}=0.125$; and $99.7 \%$ for the blank-holder force $9 \mathrm{kN}$ and $f_{\text {init }}=0.11$. The conformity of the strip drawing forces has been calculated as the ratio simulated to measured value expressed in percentage.

The conformity of the friction coefficients has been calculated as the ratio calculated to the initial value expressed in percentage. Consequently, the conformity of the friction coefficients was 100\% when calculated from Eq. (1) for each simulation performed. The conformity of the friction coefficients from 90 to $100.1 \%$ has been found when calculated from Eq. (13).

The values of the strip drawing (pulling) forces $F_{p\left(f_{3}=0\right)}$ and $F_{p\left(f_{3}>0\right)}$ when experimentally measured and numerically simulated for the type of contact 
Table 3: The friction coefficients calculated for the strip drawing test without bending (Fig. 4).

\begin{tabular}{|c|c|c|c|c|}
\hline \multirow[b]{2}{*}{ Material DX54D } & \multirow{2}{*}{$\begin{array}{l}\text { Blankholding force } \\
\qquad F_{N}[\mathrm{~N}]\end{array}$} & \multirow{2}{*}{$\begin{array}{l}\text { Drawing forces } \\
\qquad \begin{array}{c}F_{f i N} \\
{[\mathrm{~N}]}\end{array}\end{array}$} & \multicolumn{2}{|c|}{ Friction coefficients } \\
\hline & & & $\begin{array}{c}f_{1,2} \\
\text { acc. to eq. (1) }\end{array}$ & $\begin{array}{c}f_{1,2} \\
\text { acc. to eq. (13) }\end{array}$ \\
\hline \multirow{2}{*}{ Simulation, $f_{\text {initial }}=0.125$} & 4000 & 999 & 0.125 & - \\
\hline & 9000 & 2254 & 0.125 & 0.126 \\
\hline \multirow{2}{*}{ Simulation, $\mathrm{f}_{\text {initial }}=0.11$} & 4000 & 878 & 0.11 & - \\
\hline & 9000 & 1981 & 0.11 & 0.11 \\
\hline \multirow{2}{*}{ Experiment } & 4000 & 998 & 0.125 & \\
\hline & 9000 & 1986 & 0.11 & 0.099 \\
\hline \multirow{2}{*}{ Simulation and Experiment conformity [\%] } & 4000 & 100.1 & 100 & - \\
\hline & 9000 & 99.7 & 100 & $90 \div 100.1$ \\
\hline
\end{tabular}

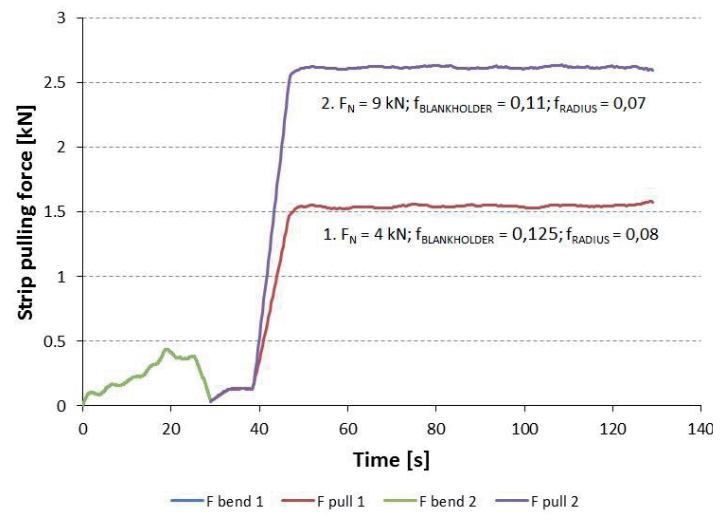

Fig. 7: The strip bending and pulling force when simulated for various initial data.

under the blank-holder and the die radius are shown in the Tab. 3. The friction coefficients on the die radius $f_{3}$ according to Eq. (17) has been calculated additionally to the friction coefficient under the blank-holder $f_{1,2}$ when calculated from the analytical equations (1) and (13).

The strip pulling forces have been calculated from the force to time curves, as it is shown in Fig. 7. Due to curve oscillation, MVA25 filter (Moving Average Filter of 25-window width) was applied. Consequently, the average value of strip pulling force has been calculated within the period $<60,120\rangle$ seconds.

The average strip pulling force was $1.546 \mathrm{kN}$ when the blank-holder force $4 \mathrm{kN}$ and friction coefficients $f_{1,2}=0.125$ and $f_{3}=0.08$ were set. Otherwise, the average strip pulling force $2.619 \mathrm{kN}$ was calculated when the blank-holder force $9 \mathrm{kN}$ and friction coefficients $f_{1,2}=0.11$ and $f_{3}=0.07$ were set. The average strip pulling forces for other combinations are presented in Tab. 4. The strip bending force, shown as the local maximum on the initial part of the curve, was $0.439 \mathrm{kN}$ and it was independent of the blank-holder force and friction conditions.

Simulation and experiment conformity of the strip drawing force varied from 100 to 120\% for the rotating cylinder and 99 to 123\% for the fixed cylinder. The conformity of the friction coefficients varied from 119 to $136 \%$ when calculated from Eq. (1) for each simulation performed. Better conformity of the friction coefficients - 100 to $106 \%$ - has been found when calculated from Eq. (13). Otherwise, the conformity of the friction coefficients varied from 93 to $100 \%$ when calculated from Eq. (17).

When compare the calculated friction coefficients, these decrease with the blank-holder force rising for each type of contact. The finding complies with Fuchs concern declaration for Anticorit lubricant, which contains high-pressure additives and proves increased efficiency with the load increasing.

The friction coefficients $f_{1,2}$ under the blank-holder calculated from Eq. (1) have shown the difference up to $36 \%$ than friction coefficients calculated from Eq. (13) with the difference $6 \%$, when calculated for the strip drawing test with bending for the fixed and the rotate cylinder. This is because the Eq. (13) includes the ratio of differences the pulling and the blank-holder forces. Thus, it eliminates the influence of the bending force, friction in bearings and other factors. However, the same difference $7 \%$ have been found when to calculate the friction coefficients $f_{3}$ on the die radius from Eq. (17). Consequently, the friction model in the simulation software presents good conformity to the experimentally measured results. 
Table 4: The friction coefficients calculated for the strip drawing test with bending (Fig. 5).

\begin{tabular}{|c|c|c|c|c|c|c|}
\hline \multirow[b]{2}{*}{ Material DX54D } & \multirow[b]{2}{*}{$\begin{array}{c}\text { Blank- } \\
\text { holding force } \\
F_{N}[\mathrm{~N}]\end{array}$} & \multicolumn{2}{|c|}{ Drawing forces } & \multicolumn{3}{|c|}{ Friction coefficients } \\
\hline & & $\begin{array}{l}\text { Rotating } \\
\text { cylinder } \\
F_{p\left(f_{3}=0\right)}[\mathrm{N}]\end{array}$ & $\begin{array}{c}\text { Fixed } \\
\text { cylinder } \\
F_{p\left(f_{3}>0\right)}[\mathrm{N}]\end{array}$ & $\begin{array}{c}f_{1,2} \\
\text { acc. to eq. (1) }\end{array}$ & $\begin{array}{c}f_{1,2} \\
\text { acc. to eq. (13) }\end{array}$ & $\begin{array}{c}f_{3} \\
\text { acc. to eq. (17) }\end{array}$ \\
\hline \multirow{2}{*}{ Simulation, finitial = 0.125} & 4000 & 1362 & 1546 & 0.170 & & 0.08 \\
\hline & 9000 & 2631 & - & 0.146 & 0.127 & \\
\hline \multirow{2}{*}{ Simulation, finitial $=0.11$} & 4000 & 1246 & - & 0.156 & & \\
\hline & 9000 & 2365 & 2619 & 0.131 & 0.117 & 0.065 \\
\hline \multirow{2}{*}{ Experiment } & 4000 & 1108 & 1258 & 0.125 & & 0.08 \\
\hline & 9000 & 2361 & 2646 & 0.11 & 0.099 & 0.07 \\
\hline \multirow{2}{*}{$\begin{array}{c}\text { Simulation and Experiment } \\
\text { conformity [\%] }\end{array}$} & 4000 & 120 & 123 & 136 & - & 100 \\
\hline & 9000 & 100 & 99 & 119 & $100 \div 106$ & 93 \\
\hline
\end{tabular}

Numerical simulation allows evaluating the normal contact pressure on the elements. Thus, it has been evaluated under the blank holder and on the die radius (Fig. 8). The maximum value was found at the start of the die radius with the value 23.2 and 32.3 $\mathrm{MPa}$. The normal contact pressure development along the die radius is shown in Fig. 9. The second local maximum has been found at the wrapping angle $50.6^{\circ}$ with the value $14.3 \mathrm{MPa}$ for the blankholder force $4 \mathrm{kN}$ and at the wrapping angle $61.9^{\circ}$ with the value 20.4 MPa for the blank-holder force $9 \mathrm{kN}$. The normal contact pressure under the blankholder is considerably lower.

\section{Conclusions}

The friction coefficient is one of the important data necessary to measure as input data for numerical simulations. There are presented in the paper some analytical equations to calculate the friction coefficients in the deep drawing under the blank-holder and on the die radius. The equations have been used to calculate the friction coefficients from the numerical simulations of the strip drawing test. The results were verified by the physical model of the strip drawing test when measured for various blank-holder forces and Anticorit lubricant. The friction model in the simulation software has shown good conformity to the experimentally measured results. The normal contact pressure under the blank-holder and on the die radius was also evaluated from numerical simulations. The highest value was found at the start of the die radius and the second local maximum was found on the wrapping angle 50 to 60 degrees. It is supposed the normal

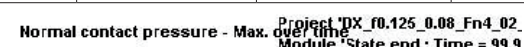

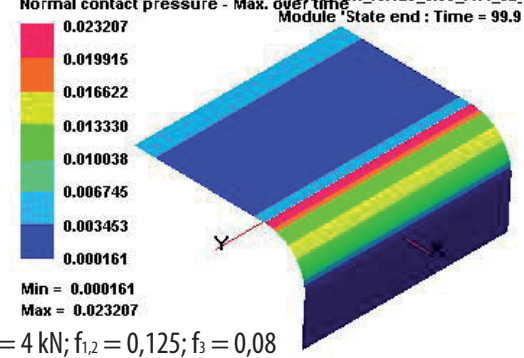

(a) $F_{N}=4 k N ; f_{1,2}=0,125 ; f_{3}=0,08$

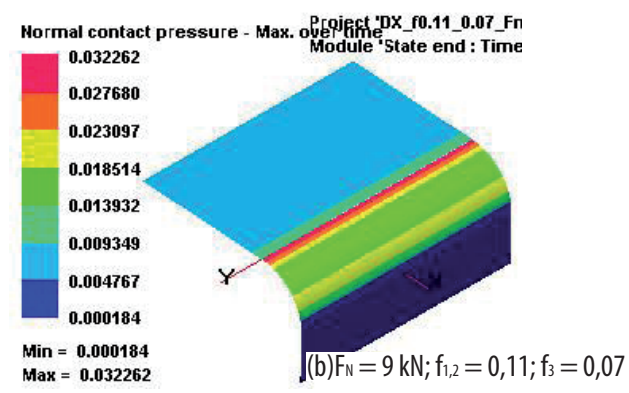

Fig. 8: The normal contact pressure during strip drawing simulation.

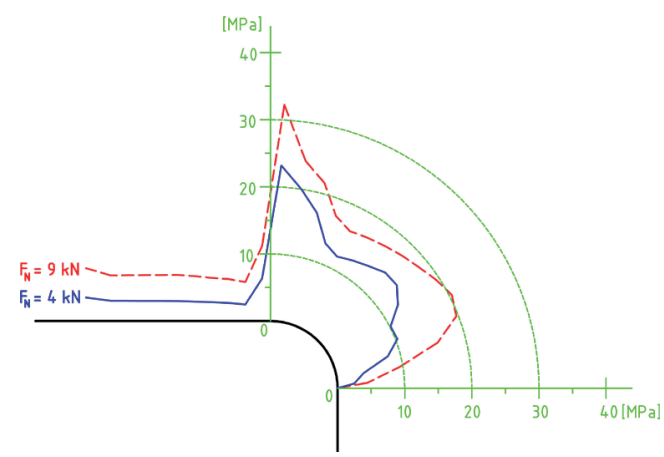

Fig. 9: The normal contact pressure under the blank-holder and on the die radius. 
contact pressure is one of the factor causes galling of the material during deep drawing.

\section{Acknowledgements}

The work has been accomplished under the grant project VEGA 2/0113/16 "Influence of laser welding parameters on structure and properties of welded joints of advanced steels for the automotive industry" and project APVV-0273-12 "Supporting innovations of autobody components from the steel sheet blanks oriented to the safety, the ecology and the car weight reduction."

\section{References and Notes}

[1] Doege E., Droder B., Greisbach B. (1997). On development of new characteristic value for the evaluation of sheet metal formability. Journal of Materials Processing Technology, Vol. 71, p. 152-159.

[2] Lange K. (1990). Umformtechnik - Blechbearbeitung. Springer/Verlag, Berlin.

[3] Mahrenholtz O., Bontcheva N. (2005). Influence of surface roughness on friction during metal forming processes. Journal of Materials Processing Technology, Vol. 159, p. 9-16.

[4] Kim Y.S., Jain M.K., Metzger D.R. (2012). Determination of pressure-dependent friction coefficient from draw-bend test and its application to cup drawing. International Journal of Machine Tools \& Manufacture, Vol. 56, p. 69-78.

[5] Schrek A., Gajdošová V., Švec P. (2016). Deformation Properties of Tailor Welded Blank Made of Dual Phase Steels. Acta Mechanica et Automatica, Vol. 10, p. 38-42.

[6] Ma G., Huang B. (2014). Optimization of Process Parameters of Stamping Forming of the Automotive Lower Floor Board. Journal of Applied Mathematics, Vol. 2014, doi:10.1155/2014/470320

[7] Wen Y., Zhong W., Liu Y. (2013). Optimization design of process parameters in sheet metal drawing. Journal of Plasticity Engineering, Vol. 20, No. 3, p. 31-36.

[8] Volk M., Nardin B., Dolšak B. (2011). Application of numerical simulations in deep-drawing process and holding system with segments' inserts. Strojniški vestnik - Journal of Mechanical Engineering, Vol. 57, No. 9, p. 697-703.

[9] Trzepieciński T., Hirpa G. (2015). Proposal for an Experimental-Numerical Method for Friction Description in Sheet Metal Forming. Journal of Mechanical Engineering. Vol. 61 p. 383-391.

[10] Zhenyu H., Vollertsen F. (2004). A new friction test method. Journal for Technology of Plasticity, Vol. 29, p.1-9

[11] Vollertsen F., Zhenyu H. (2008). Determination of size dependent friction functions in sheet metal forming with respect to the distribution of contact pressure. Production Engineering - Research and Development, Vol. 2, p. 345350 .
[12] Evin E., Németh S., Vyrostek M. (2014). Evaluation of Friction Coefficient of Stamping. Acta Mechanica Slovaca, Vol. 18, p. 20-27. ISSN 1335-2393.

\section{Biographical notes}

Emil Evin, prof. Ing. CSc., (born in 1956) is a professor in the scientific area of Engineering Technologies and Materials, Faculty of Mechanical Engineering, Technical University in Kosice. He graduated the Faculty of Mechanical Engineering, Technical University in Kosice (1980). He inaugurated as a professor in 2010 with his work "Verification of numerical simulation of formability of high strength steel sheets" in the field of Mechanical Engineering Technologies and Materials. Prof. Evin passed through the study and lecture stays in Technische Hochshule Zwickau, Technical University in Kielce, Technical Universities in Maribor and Ljubljana; and Technical University in Chemnitz. Long term, his scientific and research activities are oriented to the field of technological prediction of formability of steel sheets with higher strength properties, testing of material properties of steel sheets, simulation of stamping processes, the evaluation of the technical-economic level of production and engineering products. Prof. Evin was the principal investigator of 4 VEGA and 1 APVV projects, co-partner of several national VEGA, APVV and international scientific research projects and dozens of projects for practice. His activities in the Technical University in Kosice: Head of Department of Automotive Production, Deputy Head of Department, Member of Scientific Committee of Zeszyty Naukowe Instytutu Pojazdów - Proceedings of the Institute of Vehicles Faculty Of Automotive And Construction Machinery Engineering Warsaw University of Technology, Member of the Faculty Commission "Mechanical Engineering Technologies and Materials" Examination Commission for a doctoral level of study at the MTFSTU Trnava, expert and judge (reviewer) of the Slovak National Accreditation Service. He is the co-author of one monograph, five university textbooks and over 230 original scientific papers published in domestic and foreign journals and proceedings.

Miroslav Tomáš, Ing., PhD., (born in 1973) is assistant professor at the Technical University of Košice, Faculty of Mechanical Engineering, Department of Computer Support of Technology. He graduated in 1996 at the Technical University of Košice in 23-07-8 Mechanical Engineering Technology. He obtained PhD. degree in 2001 in research of multi-operation deep drawing process at the Technical University of Košice. His research activities are aimed at material formability tests, testing methods to determine limits of forming, numerical simulation of forming, die design in CAD/CAM systems and 3D modelling. He is an author/co-author of three textbooks, one his paper was published in Current Contents journal and seven papers were registered in Web of Science and SCOPUS. 